\title{
Accelerated Dobutamine Stress Echocardiography Protocol versus the Standard One in the Assessment of Coronary Artery Disease
}

\author{
Ahmed Bendary, Hani Alkhazragy ${ }^{1}$, Alshaymaa Sabry, Mohamed Osama' ${ }^{1}$, Khalid Elrabbat \\ Department of Cardiology, Faculty of Medicine, Benha University, Benha, ${ }^{1}$ National Heart Institute, Giza, Egypt \\ ORCID: \\ Ahmed Bendary: https://orcid.org/0000-0002-0161-3779
}

\section{Abstract}

Objectives: The steady-state concentration of dobutamine at any infusion rate is not reached except after 10 min. Nevertheless, dobutamine stress echocardiography (DSE) still employs an incremental 3-min interval infusion protocol. Constant infusion of a higher dobutamine dose appears to overcome this pitfall. We aimed to evaluate the safety and efficacy of an accelerated DSE protocol for the assessment of coronary artery disease. Methods: From June 2018 to January 2019, forty consecutive patients underwent accelerated protocol for DSE (constant infusion of $50 \mu \mathrm{g} / \mathrm{kg} / \mathrm{min}$, with discontinuation of infusion at $10 \mathrm{~min}$ if no stress endpoint appears). Their hemodynamic responses and adverse effects' profile were compared to a control group (40 patients who underwent the standard protocol within the preceding 6 months). Results: Both groups were matched in all baseline characteristics. Peak heart rate (HR) (143 \pm 13 vs. $145 \pm 13$ bpm, $P=0.54)$ and peak systolic blood pressure $(160 \pm 29$ vs. $155 \pm 42 \mathrm{mmHg}, P=0.53)$ were similar in both protocols. The accelerated protocol produced a significantly more rapid increase in HR $(11.5 \pm 2.3$ vs. $5.3 \pm 1.3 \mathrm{bpm}, P<0.001)$ and resulted in marked reduction in test duration $(6 \pm 2 \mathrm{vs} .14 \pm 3 \mathrm{~min}, P<0.001)$. The mean total cumulative dobutamine dose was lower in the accelerated group ( $275 \pm 63 \mathrm{vs.} 355 \pm 144 \mu \mathrm{g} / \mathrm{kg}, P=0.029)$. Both groups experienced similar rates of both arrhythmic and nonarrhythmic adverse effects. Conclusion: Accelerated DSE protocol seems as feasible, safe, effective, and more time-saving compared to the standard one. This might be of value to busy echocardiographic laboratories.

Keywords: Coronary artery disease, dobutamine, stress echocardiography

\section{INTRODUCTION}

Dobutamine stress echocardiography (DSE) is one of the commonly employed daily tests for the evaluation of the extent and severity of coronary artery disease (CAD) in addition to myocardial viability. ${ }^{[1]}$ Pharmacologically, the steady-state concentration of dobutamine required for a full effect (at any infusion rate) is not reached except after $10 \mathrm{~min}^{\left[{ }^{[2,3]}\right.}$ Nevertheless, DSE is still being performed with an incremental 3-min interval infusion protocol derived as a simulation to the commonly used exercise treadmill protocols. The net result is that the full effect of any infusion rate of dobutamine is not obtained before the next rate of infusion is due, resulting in a rapid nonlinear increase in the dobutamine plasma concentration

\begin{tabular}{l} 
Submission: 08-Apr-19 Revision: 06-May-19 Accepted: 13-May-19 \\
Published Online: 25-Nov-19 \\
Access this article online \\
Quick Response Code: \\
\hline
\end{tabular}

during the test. ${ }^{[4,5]}$ Moreover, prior studies have consistently showed that patients who cannot stop $\beta$-blockers before DSE usually fail to achieve target heart rate (HR) and that the addition to atropine could enhance the sensitivity of the test by improving HR response ${ }^{[6]}$ Accordingly, infusion of a continuous and high single-dose of dobutamine has been suggested as a potentially more simple, feasible, and effective method for stress induction in DSE, and this has been evaluated in few studies. ${ }^{[7-12]} \mathrm{We}$

Address for correspondence: Dr. Ahmed Bendary, Department of Cardiology, Faculty of Medicine, Benha University, Fareed Nada Street, Benha, Egypt. E-mail: ahmed.bendari@fmed.bu.edu.eg

This is an open access journal, and articles are distributed under the terms of the Creative Commons Attribution-NonCommercial-ShareAlike 4.0 License, which allows others to remix, tweak, and build upon the work non-commercially, as long as appropriate credit is given and the new creations are licensed under the identical terms.

For reprints contact: reprints@medknow.com

How to cite this article: Bendary A, Alkhazragy H, Sabry A, Osama M, Elrabbat K. Accelerated dobutamine stress echocardiography protocol versus the standard one in the assessment of coronary artery disease. Int $\mathrm{J}$ Cardiovasc Acad 2019;5:141-5. 
thought that it might be of considerable interest if we could reiterate these findings among our patient population.

\section{Methods}

\section{Study design}

Forty consecutive patients referred for a clinically indicated DSE were prospectively enrolled in this observational case-control study from June 2018 to January 2019. Another 40 consecutive patients who underwent standard DSE during the past 6 months served as controls. Clinical indications for DSE were the evaluation of angina pectoris in patients with intermediate pretest probability for $\mathrm{CAD}$, evaluation of patients with atypical chest pain, and for those with uninterpretable electrocardiograms (ECGs) at baseline. Exclusion criteria were a recent myocardial infarction (within 3 days), unstable angina, recent ventricular tachycardia, atrial fibrillation with the rapid ventricular response, severe hypertension, and significant aortic stenosis. Concurrent medications were continued at the discretion of the referring physician. The study was approved by our local ethical committee and written informed consents were obtained from all patients.

\section{Dobutamine stress echocardiographic procedure}

Baseline two-dimensional (2-D) transthoracic echocardiographic examination (Philips EPIQ 7 Ultrasound System, Andover, MA, USA) was performed in the standard views (parasternal long- and short-axis, apical 2- and 4-chamber views), and a 12-lead ECG at rest was obtained.

\section{Standard dobutamine-atropine infusion protocol}

Dobutamine was infused with 3-min dose increments, starting from $5 \mu \mathrm{g} / \mathrm{kg} / \mathrm{min}$ and increasing to $10,20,30,40$, and $50 \mu \mathrm{g} / \mathrm{kg} / \mathrm{min}$. The ECG was monitored throughout dobutamine infusion and recorded each minute. Cuff blood pressure (BP) was measured at rest, every 3 min during stress, and at maximal stress. When no endpoint was reached, atropine $(0.5-1.0 \mathrm{mg})$ was given to the continuing $40 \mu \mathrm{g} / \mathrm{kg} / \mathrm{min}$ dobutamine infusion stage if no contraindications such as glaucoma or prostatic enlargement were present. The infusion was terminated after the maximal dose was reached or at 1 of the following end points:

- More than $85 \%$ of the age-predicted maximal HR

- A decrease in BP of $>40 \mathrm{~mm} \mathrm{Hg}$ from the resting value or a systolic BP (SBP) of $<90 \mathrm{~mm} \mathrm{Hg}$

- The occurrence of severe hypertension (SBP of $>240 \mathrm{~mm} \mathrm{Hg}$ or diastolic BP of $>120 \mathrm{~mm} \mathrm{Hg}$ )

- $\quad$ Significant cardiac arrhythmias

- Severe chest pain

- Horizontal or downsloping ECG ST depression of $\geq 1 \mathrm{~mm}$ measured $80 \mathrm{~ms}$ after the $\mathrm{J}$ point or ST-segment elevation $\geq 1 \mathrm{~mm}$ in the absence of $\mathrm{Q}$ waves

- Marked new echocardiographic regional wall motion abnormalities in multiple locations

- Severe vagal reactions or other intolerable noncardiac symptoms.
Metoprolol was available and was administered intravenously (2.5-5 mg) to reverse the effects of dobutamine if these did not revert spontaneously or rapidly.

\section{Accelerated protocol}

Dobutamine was administered at a constant dose of $50 \mu \mathrm{g} / \mathrm{kg} / \mathrm{min}$ for up to $10 \mathrm{~min}$. Early echocardiographic images were obtained starting at $20 \mathrm{~s}$ (roughly corresponding to the cumulative dose given over $3 \mathrm{~min}$ at $5 \mu \mathrm{g} / \mathrm{kg} / \mathrm{min}$ ). When no endpoint was reached, atropine $(0.5$ or $1.0 \mathrm{mg})$ was given to the continuing $50 \mu \mathrm{g} / \mathrm{kg} / \mathrm{min}$ dobutamine infusion at 5 min into the study in the absence of contraindications, and repeated to a maximum of $1.0 \mathrm{mg}$, if necessary. Dobutamine infusion was discontinued after $10 \mathrm{~min}$ or for 1 of the endpoints mentioned above.

\section{Images interpretation}

Off-line assessment of echocardiographic images was performed by an investigator who was blinded to clinical information, ECG findings, and study protocol. Regional wall motion was assessed according to the recommendations of the American Society of Echocardiography using a 17-segment model, ${ }^{[13]}$ and wall motion was graded as follows: $1=$ normal, 2 = hypokinetic, $3=$ akinetic, and $4=$ dyskinetic. $^{[13]}$ The test was considered positive when wall motion in any segment deteriorated $>1$ grade, except for a change from resting akinesia to dyskinesia. ${ }^{[14]}$ Studies were identified as nondiagnostic if the patient reached $85 \%$ age-predicted maximal HR in the absence of inducible ischemia. For each individual patient, 2-D echocardiographic images were recorded at baseline, low dose, peak stress, and during recovery. Images of 4 standard imaging planes were digitized and displayed in a standard quad-screen digital format that allowed offline side by side comparison.

\section{Statistical analysis}

Data management and statistical analysis were done using SPSS version 25. (IBM, Armonk, New York, United states). Numerical data were summarized as means and standard deviations. Categorical data were summarized as numbers and percentages. Before running comparisons, numerical data were assessed for normality using normality tests and direct visualization methods. Comparisons between two groups were done using independent $t$-test for numerical variables. In comparisons limited only for patients using $\beta$-Blockers; Mann-Whitney U-test (nonparametric test) was used due to relatively small numbers in both groups. Categorical data were compared using the Chi-square test or Fisher's exact test if appropriate. All $P$ values were two-sided. Values of $P<0.05$ were considered statistically significant.

\section{RESULTS}

\section{Baseline characteristics}

The study participants consisted of 80 patients ( 43 males, mean age $56 \pm 10$ years). All patients had limited exercise capacity 
and intermediate pre-test probability ${ }^{[15]}$ for CAD. They were referred for a clinically indicated DSE to evaluate anginal symptoms. Forty patients underwent accelerated protocol for DSE, and 40 patients underwent the standard protocol. Among the whole study population, 58 patients had angina pectoris, 14 patients had atypical chest pain, and 8 patients had uninterpretable ECG at baseline. There were no statistically significant differences between both groups regarding various baseline criteria [Table 1].

\section{Hemodynamic data}

No statistically significant differences were seen between both groups regarding baseline HR ( $74 \pm 9$ vs. $74 \pm 11$ bpm, $P=0.991$ for accelerated and standard groups, respectively) and baseline SBP $(119 \pm 10$ vs. $121 \pm 10 \mathrm{mmHg}, P=0.355$ for accelerated and standard groups, respectively). Patients in the accelerated protocol achieved a significantly more rapid increase in HR compared to those in the standard protocol ( $11.5 \pm 2.3$ vs. $5.3 \pm 1.3 \mathrm{bpm}$, respectively, $P<0.001$ ). Peak HR, peak SBP, and percent of patients achieving target HR were similar between both groups [Table 2].

\section{Echocardiographic data}

There were no statistically significant differences between both groups regarding wall motion score index, left ventricular end-diastolic volume, left ventricular end-systolic volume, and left ventricular ejection fraction (LVEF) both at rest and at peak stress [Table 3].

\section{Test parameters}

Patients who underwent the accelerated protocol had a significantly shorter stress times compared to those who underwent the standard protocol ( $6 \pm 2$ vs. $14 \pm 3 \mathrm{~min}$ respectively, $P<0.001$ ) [Figure 1a]. Moreover, the total cumulative dobutamine dose was significantly lesser in the group of the accelerated protocol $(275 \pm 63$ vs. $355 \pm 144 \mu \mathrm{g} / \mathrm{kg}, P=0.029$ ) [Figure 1b]. There was no statistically significant difference between accelerated and standard protocol groups in the frequency of atropine use ( 12.5 vs. $10 \%$, respectively, $P=1)$ nor in the final test results (positive in 35 vs. $37.5 \%$, respectively, $P=0.816$ ) with others being negative. No tests were reported to be nonconclusive.

\section{Effect of $\beta$-blockers}

Among patients who did not stop $\beta$-blockers before the test (31 patients), differences observed between accelerated and standard protocols for the entire population were also maintained. This included a significantly shorter stress time, lesser total cumulative dobutamine dose, and a more rapid HR increase. Again, with similar peak SBP, peak HR, percent achieving target HR, and percent use of atropine [Table 4].

\section{Test tolerability}

No major complications occurred in either group. There were no statistically significant differences between accelerated and standard protocol groups regarding occurrence of both arrhythmic side effects ( $30 \%$ vs. $32.5 \%, P=0.809)$ and nonarrhythmic side effects ( 27.5 vs. $30 \%, P=0.805)$. Table 5 shows the frequency of adverse effects and arrhythmias induced in both DSE protocols. The most frequent nonarrhythmic side effect was hypotension, which occurred in six patients and warranted termination of the test in only 1 patient. All arrhythmic episodes were asymptomatic and did not warrant test termination in any patient.

\section{Discussion}

In the present study, a single, high, and continuous infusion of dobutamine for stress induction in DSE appears as safe

\begin{tabular}{|c|c|c|c|}
\hline & $\begin{array}{l}\text { Accelerated } \\
\text { regimen } \\
(n=40)\end{array}$ & $\begin{array}{l}\text { Standard } \\
\text { regimen } \\
(n=40)\end{array}$ & $P$ \\
\hline Age (years), mean $\pm \mathrm{SD}$ & $57 \pm 10$ & $56 \pm 11$ & 0.635 \\
\hline \multicolumn{4}{|l|}{ Gender } \\
\hline Males & $21(52.2)$ & $22(55.0)$ & \multirow[t]{2}{*}{0.823} \\
\hline Females & $19(47.5)$ & $18(45.0)$ & \\
\hline DM (yes) & $21(52.5)$ & $20(50.0)$ & 0.823 \\
\hline HTN (yes) & $25(62.5)$ & $24(60.0)$ & 0.818 \\
\hline smoker (yes) & $17(42.5)$ & $19(47.5)$ & 0.653 \\
\hline Dyslipidemia (yes) & $15(37.5)$ & $16(40.0)$ & 0.818 \\
\hline Obesity (yes) & $24(60.0)$ & $23(57.5)$ & 0.82 \\
\hline $\mathrm{FH}$ of premature CAD (yes) & $11(27.5)$ & $13(32.5)$ & 0.626 \\
\hline \multicolumn{4}{|l|}{ Clinical indication for DSE } \\
\hline Angina pectoris & $30(75)$ & $28(70)$ & \multirow[t]{3}{*}{0.837} \\
\hline Atypical chest pain & $6(15)$ & $8(20)$ & \\
\hline Uninterpretable ECG & $4(10)$ & $4(10)$ & \\
\hline Weight $(\mathrm{kg})$ & $87 \pm 6$ & $87 \pm 7$ & 0.806 \\
\hline Height (cm) & $175 \pm 10$ & $175 \pm 10$ & 0.886 \\
\hline BB use (yes) & $15(37.5)$ & $16(40.0)$ & 0.818 \\
\hline CCB use (yes) & $16(40.0)$ & $15(37.5)$ & 0.818 \\
\hline Dihydropyridine & $12(75)$ & $13(86.6)$ & 0.653 \\
\hline Nondihydropyridine & $4(25)$ & $2(13.3)$ & \\
\hline Both BB and CCB use (yes) & $10(25.0)$ & $8(20.0)$ & 0.592 \\
\hline \multicolumn{4}{|c|}{$\begin{array}{l}\text { *Independent } t \text {-test was used for age. Chi-square test was used } \\
\text { for categorical data. BB: Beta blockers, CAD: Coronary artery } \\
\text { disease, CCB: Calcium channel blocker, DSE: Dobutamine stres } \\
\text { echocardiography, DM: Diabetes mellitus, FH: Family history, } \\
\text { HTN: Hypertension, ECG: Electrocardiogram, SD: Standard dev }\end{array}$} \\
\hline
\end{tabular}

\begin{tabular}{|c|c|c|c|}
\hline & $\begin{array}{l}\text { Accelerated } \\
\text { regimen } \\
(n=40)\end{array}$ & $\begin{array}{c}\text { Standard } \\
\text { regimen } \\
(n=40)\end{array}$ & $P$ \\
\hline HR at rest (bpm), mean \pm SD & $74 \pm 9$ & $74 \pm 11$ & 0.991 \\
\hline Peak HR (bpm), mean \pm SD & $143 \pm 13$ & $145 \pm 13$ & 0.54 \\
\hline $\begin{array}{l}\text { Increase in HR per min (bpm), } \\
\text { mean } \pm \text { SD }\end{array}$ & $11.5 \pm 2.3$ & $5.3 \pm 1.3$ & $<0.001$ \\
\hline Target HR achieved?, yes & $37(92.5)$ & $36(90.0)$ & 1 \\
\hline $\mathrm{SBP}$ at rest $(\mathrm{mmHg})$, mean $\pm \mathrm{SD}$ & $119 \pm 10$ & $121 \pm 10$ & 0.355 \\
\hline Peak SBP (mmHg), mean \pm SD & $160 \pm 29$ & $155 \pm 42$ & 0.529 \\
\hline
\end{tabular}

*Independent $t$-test was used for numerical data. Fisher's exact test was used for target HR achieved. HR: Heart rate, SBP: Systolic blood pressure, SD: Standard deviation 
and effective as the standard protocol. This finding reaffirms other few previous studies examining the issue ${ }^{[7-12]}$ and adds to the accumulating body of evidence supporting the use of the accelerated DSE protocol.

Similar to Burger et al. ${ }^{\left[{ }^{[1]}\right.}$ and Minardi et al. ${ }^{[11]}$ we showed that the accelerated protocol resulted in a more rapid increase in HR, which enabled patients to achieve their target HR rapidly resulting in significantly shorter stress time and lower total cumulative dobutamine dose compared to the standard protocol.

\begin{tabular}{|c|c|c|c|}
\hline & \multicolumn{2}{|c|}{ Mean $\pm S D$} & \multirow[t]{2}{*}{$P$} \\
\hline & $\begin{array}{c}\text { Accelerated } \\
\text { regimen }(n=40)\end{array}$ & $\begin{array}{c}\text { Standard } \\
\text { regimen }(n=40)\end{array}$ & \\
\hline \multicolumn{4}{|l|}{ WMSI } \\
\hline Rest & $1.03 \pm 0.14$ & $1.03 \pm 0.11$ & 0.921 \\
\hline Stress & $1.12 \pm 0.2$ & $1.13 \pm 0.28$ & 0.888 \\
\hline \multicolumn{4}{|l|}{ LVEDV } \\
\hline Rest (ml) & $133 \pm 19$ & $135 \pm 29$ & 0.75 \\
\hline Stress (ml) & $116 \pm 20$ & $128 \pm 33$ & 0.071 \\
\hline \multicolumn{4}{|l|}{ LVESV } \\
\hline Rest (ml) & $55 \pm 11$ & $56 \pm 17$ & 0.731 \\
\hline Stress (ml) & $42 \pm 16$ & $50 \pm 26$ & 0.129 \\
\hline \multicolumn{4}{|l|}{ EF } \\
\hline At rest $(\%)$ & $59 \pm 5$ & $59 \pm 4$ & 0.902 \\
\hline At peak stress $(\%)$ & $64 \pm 8$ & $62 \pm 12$ & 0.231 \\
\hline
\end{tabular}

The fact that the accelerated DSE protocol resulted in a shorter stress time without sacrificing safety makes sense. It implies that this protocol could be of value for some very busy laboratories with a high volume of patients referred for the assessment of CAD. However, we do not recommend the universal use of such a protocol for all patients. Cardiologists should still employ an individualized approach in test selection.

Interestingly, we demonstrated that differences between both protocols in terms of shorter stress times and lower cumulative dobutamine dose were maintained among the subgroup of patients whose physicians preferred not to stop $\beta$-blockers before the test. This gives more validity to the accelerated DSE protocol and indicates that it could be applied to a wide spectrum of patients, considering that withholding $\beta$-blockers before DSE is not always possible for all patients.

Because dobutamine in the accelerated protocol is administered in a single, high, and continuous fashion (without increments), a major concern is a potential rise in arrhythmic and ischemic adverse effects. Nevertheless, we did not find any significant increase in either arrhythmic or nonarrhythmic complications between both protocols. The explanation why the accelerated protocol did not result in a significantly higher incidence of arrhythmic complications is difficult, but we speculate that the lower total cumulative dobutamine dose could be the key player here (in light of the normal mean LVEF of the included patients). Actually, there are data from the literature supporting this theory; with some investigators suggesting that dobutamine triggers arrhythmia only in the presence of an ischemic substrate, ${ }^{[15]}$ and others demonstrating the occurrence of serious ventricular arrhythmias in doses of dobutamine as low as 20

Table 4: Test parameters in patients receiving $\beta$-blockers*

\begin{tabular}{|c|c|c|c|}
\hline & Accelerated regimen $(n=15)$ & Standard regimen $(n=16)$ & $P$ \\
\hline Stress time (min), mean \pm SD & $6 \pm 2$ & $15 \pm 3$ & $<0.001$ \\
\hline Total cumulative dobutamine dose $(\mu \mathrm{g} / \mathrm{kg})$, mean $\pm \mathrm{SD}$ & $310 \pm 76$ & $400 \pm 134$ & 0.017 \\
\hline Atropine use, yes & $1(6.7)$ & $3(18.8)$ & 0.6 \\
\hline Peak HR (bpm), mean \pm SD & $138 \pm 14$ & $140 \pm 11$ & 1 \\
\hline Increase in HR per min (bpm), mean $\pm \mathrm{SD}$ & $11.6 \pm 1.8$ & $5.2 \pm 1.2$ & $<0.001$ \\
\hline Target HR achieved, yes & $13(86.7)$ & $14(87.5)$ & 1 \\
\hline Peak SBP $(\mathrm{mmHg})$, mean \pm SD & $157 \pm 36$ & $157 \pm 36$ & 0.984 \\
\hline
\end{tabular}

*Mann-Whitney U-test was used for numerical data. Fisher's exact test was used for categorical data, HR: Heart rate, SBP: Systolic blood pressure, SD: Standard deviation

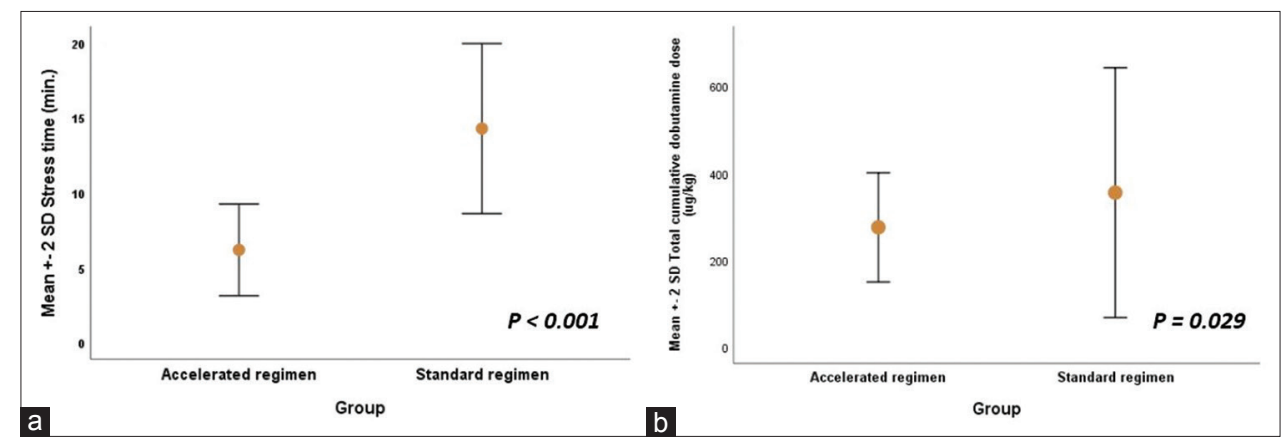

Figure 1: Total stress time (a) and total cumulative dobutamine dose (b) in both study groups 


\begin{tabular}{lcc}
\hline Table 5: Adverse effects during dobutamine stress testing \\
\hline & $\begin{array}{c}\text { Accelerated } \\
\text { protocol }(\boldsymbol{n = 4 0})\end{array}$ & $\begin{array}{c}\text { Standard } \\
\text { protocol }(\boldsymbol{n}=\mathbf{4 0})\end{array}$ \\
\hline $\begin{array}{l}\text { Nonarrhythmic side effect } \\
\text { Nausea }\end{array}$ & 2 & 2 \\
Hypotension & 3 & 3 \\
Anxiety & 1 & 2 \\
Headache & 2 & 0 \\
Anginal pain & 0 & 3 \\
Tremors & 2 & 1 \\
Severe HTN & 1 & 0 \\
Dyspnea & 0 & 1 \\
Type of arrhythmic side effect & & 8 \\
PVCs $(\geq 6 /$ min $)$ & 8 & 5 \\
PACs $(\geq 6 /$ min) & 3 & 0 \\
NSVT & 1 & \\
\hline HTN: Hypertension, NSVT: Nonsustained ventricular tachycardia, \\
PVCs: Premature ventricular contractions, PACs: Premature atrial \\
contractions
\end{tabular}

$\mu \mathrm{g} / \mathrm{kg} / \mathrm{min}$ or even after cessation of infusion! ${ }^{[16]}$ Of note, no patients in the accelerated group developed anginal pain (as a complication of the test), in contrast to three patients only in the standard group. This was unexpected given the limited exercise capacity as described in the baseline criteria of the included patients. Nevertheless, we think that this may be a play of chance due to the small sample size in the current study.

The current study is not without limitations. First, small sample size and the single-center experience lack the power to detect differences in uncommon side effects. Second, the diagnostic accuracy of DSE for detection of the presence of CAD was not evaluated in the present study, as this would require a much larger sample size and a large-scale multicenter design to determine both sensitivity and specificity. Third, although echocardiographic images in the current study were obtained starting at $20 \mathrm{~s}$ (which roughly corresponds to a low dose dobutamine of $5 \mu \mathrm{g} / \mathrm{kg} / \mathrm{min}$ ) and thus might be advocated for "viability" assessment, we should state that this work was not designed primarily to test this hypothesis. A separate standard low dose of dobutamine $(5 \mu \mathrm{g} / \mathrm{kg} / \mathrm{min})$ should be employed if the evaluation of viability is clinically needed.

\section{Conclusion}

The accelerated protocol of DSE consisting of infusion of a single, high, and continuous dose of dobutamine is as safe and effective as the standard one. It resulted in significantly shorter stress times and lower total cumulative dobutamine dose, which might translate into a more rapid patient turnover in busy laboratories. Further large-scale studies are needed to test the diagnostic accuracy of such a protocol.

\section{Acknowledgment}

We greatly appreciate contribution from Dr. Mohamed Bendary in the statistical data analysis. Comments from reviewers of the manuscript were also highly valuable.

\section{Financial support and sponsorship} Nil.

\section{Conflicts of interest}

There are no conflicts of interest.

\section{RefERENCES}

1. Sicari R, Nihoyannopoulos P, Evangelista A, Kasprzak J, Lancellotti P, Poldermans D, et al. Stress echocardiography expert consensus statement: European Association of Echocardiography (EAE) (a registered branch of the ESC). Eur J Echocardiogr 2008;9:415-37.

2. Mazeika PK, Nadazdin A, Oakley CM. Dobutamine stress echocardiography for detection and assessment of coronary artery disease. J Am Coll Cardiol 1992;19:1203-11.

3. Weissman NJ, Rose GA, Foster GP, Picard MH. Effects of prolonging peak dobutamine dose during stress echocardiography. J Am Coll Cardiol 1997;29:526-30.

4. Tuttle RR, Mills J. Dobutamine: Development of a new catecholamine to selectively increase cardiac contractility. Circ Res 1975;36:185-96.

5. Daly AL, Linares OA, Smith MJ, Starling MR, Supiano MA. Dobutamine pharmacokinetics during dobutamine stress echocardiography. Am J Cardiol 1997;79:1381-6.

6. Pingitore A, Picano E, Colosso MQ, Reisenhofer B, Gigli G, Lucarini AR, et al. The atropine factor in pharmacologic stress echocardiography. Echo persantine (EPIC) and echo dobutamine international cooperative (EDIC) study groups. J Am Coll Cardiol 1996;27:1164-70.

7. Tighe JF, Vernalis MN, Taylor AJ, Weissman NJ. Accelerated dobutamine stress echocardiography: Safety and feasability in healthy males. J Am Soc Echocardiogr 1997;10:435.

8. Burger AJ, Notarianni MP, Aronson D. Safety and efficacy of an accelerated dobutamine stress echocardiography protocol in the evaluation of coronary artery disease. Am J Cardiol 2000;86:825-9.

9. Lu D, Greenberg MD, Little R, Malik Q, Fernicola DJ, Weissman NJ, et al. Accelerated dobutamine stress testing: Safety and feasibility in patients with known or suspected coronary artery disease. Clin Cardiol 2001;24:141-5.

10. Pastorius CA, Knickelbine T, Schum K, Nelson TF, Harris KM. Tolerability and infusion time of an accelerated infusion dobutamine echocardiography protocol. Echocardiography 2007;24:393-6.

11. Minardi G, Manzara C, Pulignano G, Pino PG, Pavaci H, Sordi M, et al. Feasibility, safety and tolerability of accelerated dobutamine stress echocardiography. Cardiovasc Ultrasound 2007;5:40.

12. San Román JA, Sanz-Ruiz R, Ortega JR, Pérez-Paredes M, Rollán MJ, Muñoz AC, et al. Safety and predictors of complications with a new accelerated dobutamine stress echocardiography protocol. J Am Soc Echocardiogr 2008;21:53-7.

13. Lang RM, Bierig M, Devereux RB, Flachskampf FA, Foster E, Pellikka PA, et al. Recommendations for chamber quantification: A report from the American Society of echocardiography's guidelines and standards committee and the chamber quantification writing group, developed in conjunction with the European association of echocardiography, a branch of the European society of cardiology. J Am Soc Echocardiogr 2005; 18:1440-63.

14. Senior R, Lahiri A. Enhanced detection of myocardial ischemia by stress dobutamine echocardiography utilizing the "biphasic" response of wall thickening during low and high dose dobutamine infusion. J Am Coll Cardiol 1995;26:26-32.

15. Bittencourt MS, Hulten E, Polonsky TS, Hoffman U, Nasir K, Abbara S, et al. European society of cardiology-recommended coronary artery disease consortium pretest probability scores more accurately predict obstructive coronary disease and cardiovascular events than the diamond and forrester score clinical perspective: The partners registry. Circulation 2016;134:201-11

16. Elhendy A, van Domburg RT, Bax JJ, Roelandt JR. Relation between the extent of coronary artery disease and tachyarrhythmias during dobutamine stress echocardiography. Am J Cardiol 1999;83:832-5. 